\title{
Sandwich ELISA for quantitative detection of human collagen prolyl 4-hydroxylase
}

\author{
Ekaterina Osmekhina*1, Antje Neubauer², Katharina Klinzing' ${ }^{1}$ Johanna Myllyharju² and Peter Neubauer1,3
}

\begin{abstract}
Background: We describe a method for specific, quantitative and quick detection of human collagen prolyl 4hydroxylase (C-P4H), the key enzyme for collagen prolyl-4 hydroxylation, in crude samples based on a sandwich ELISA principle. The method is relevant to active C-P4H level monitoring during recombinant $\mathrm{C}-\mathrm{P} 4 \mathrm{H}$ and collagen production in different expression systems. The assay proves to be specific for the active C-P4H $\mathrm{a}_{2} \beta_{2}$ tetramer due to the use of antibodies against its both subunits. Thus in keeping with the method C-P4H is captured by coupled to an anti-a subunit antibody magnetic beads and an anti- $\beta$ subunit antibody binds to the PDI/ $\beta$ subunit of the protein. Then the following holoenzyme detection is accomplished by a goat anti-rabbit lgG labeled with alkaline phosphatase which AP catalyzes the reaction of a substrate transformation with fluorescent signal generation.
\end{abstract}

Results: We applied an experimental design approach for the optimization of the antibody concentrations used in the sandwich ELISA. The assay sensitivity was $0.1 \mathrm{ng}$ of C-P4H. The method was utilized for the analysis of C-P4H accumulation in crude cell extracts of E. coli overexpressing C-P4H. The sandwich ELISA signals obtained demonstrated a very good correlation with the detected protein activity levels measured with the standard radioactive assay. The developed assay was applied to optimize C-P4H production in E. coli Origami in a system where the C-P4H subunits expression acted under control by different promoters. The experiments performed in a shake flask fed-batch system $\left(\right.$ EnBase $^{\circ}$ ) verified earlier observations that cell density and oxygen supply are critical factors for the use of the inducer anhydrotetracycline and thus for the soluble C-P4H yield.

Conclusions: Here we show an example of sandwich ELISA usage for quantifying multimeric proteins. The method was developed for monitoring the amount of recombinant C-P4H tetramer in crude E. coli extracts. Due to the specificity of the antibodies used in the assay against the different C-P4H subunits, the method detects the entire holoenzyme, and the signal is not disturbed by background expression of the separate subunits.

\section{Background}

A sandwich Enzyme-Linked ImmunoSorbent Assay (ELISA) is a powerful tool for quantifying proteins and qualifying their state of activation in complex biological samples. The assay is widely used in clinical diagnostic, food samples analyzing and as a microarray in proteomic applications [1].

The method is based on the detection of hybridization events between two antibodies (capture and detection) and the target proteins. The capture antibodies are used to immobilize the protein onto a solid support and the detection antibodies are recognized by the enzyme-

* Correspondence: Ekaterina.Osmekhina@oulu.fi

1 Bioprocess Engineering Laboratory, Department of Process and Environmental Engineering, P.O.Box 4300, FIN-90014 University of Oulu, Finland Full list of author information is available at the end of the article linked secondary antibodies. The linked enzyme catalyzes substrate transformation reactions with generation of a detectable signal.

The sandwich ELISA has certain advantages compared to a standard ELISA: firstly, the ability to use crude or impure samples and still selectively bind an antigen of interest; and, secondly, a better specificity since the antibodies against different epitopes of a target protein are used. We apply the sandwich ELISA for complex proteins measuring in crude cell extracts. In this case the capture and detection antibodies are specific to different subunits of a target protein, due to which only proteins containing both subunits are sensed using the assay.

Here we describe a sandwich ELISA for recombinant human collagen prolyl 4-hydroxylase (C-P4H) detection in crude cell extracts. 
Collagen prolyl 4-hydroxylases play a central role in the synthesis of collagens and collagen-like proteins. The human C-P4Hs are $\alpha_{2} \beta_{2}$ tetramers with a total size of 240 $\mathrm{kDa}$. The $\alpha$ subunits contain the catalytic sites and the $\beta$ subunits keep the protein in a soluble and active state. The $\beta$ subunit is identical to the enzyme and chaperone protein disulphide isomerase (PDI) [2], one of the most abundant proteins in the endoplasmic reticulum.

Serum C-P4H levels increase in patients with liver cirrhosis, alcoholic hepatitis, acute hepatitis, hepatocellular carcinoma, and cholestatic diseases, and it can be used as a biochemical marker for these diseases [3-6]. As C-P4H is a potential target for treatment of fibrotic diseases, a big interest exists in recombinant expressed C-P4H used for detailed functional and structural studies. Furthermore, C-P4H coexpression is required for recombinant collagen production in different expression systems. An active recombinant human C-P4H tetramer assembly has been successfully achieved in various cell types for above mentioned investigations [7-14]. C-P4H can be efficiently expressed and assembled in yeast, plant and animal cells, but the product yields are rather low. Therefore, recombinant expression systems using the well characterized and fast growing bacterium Escherichia coli as a host organism were developed, and they are aimed at large scale production of the target enzyme in high cell density cultivations [14-16].

In such production systems, C-P4H accumulation and activity was monitored by Western blotting, the enzyme activity measurement in radioactive [17] and radioactivity-free [18] assays, analysis of $\alpha$ and $\beta$ subunits expression at mRNA level with sandwich hybridization [16]. But the exact level of the produced C-P4H tetramer can be accurately measured only after HPLC purification of the protein.

A commercially available immunoassay (Fuji Chemicals, Toyama, Japan; [19]) used for the C-P4H analysis in serum is based on the process of protein capturing and detection via the PDI $/ \beta$ subunit. This method detects both C-P4H tetramers and free PDI/ $\beta$ subunits, but it is entirely unable to distinguish between them. Since PDI $\beta$ subunit expression is induced before the $\alpha$ subunit one during recombinant $\mathrm{C}-\mathrm{P} 4 \mathrm{H}$ production in $E$. coli cells, the $\mathrm{PDI} / \beta$ subunit proves to be synthesized in a large excess over the $\alpha$ subunit [14]. The $\alpha$ subunits aggregate immediately if they are recombinantly produced alone or if the $\mathrm{C}-\mathrm{P} 4 \mathrm{H}$ tetramer is dissociated [2]. The $\mathrm{PDI} / \beta$ subunit is also present in excess amounts relative to the $\alpha$ subunit in vivo.

In the sandwich ELISA described here the capture and detection antibodies are specific to the C-P4H $\alpha$ and PDI/ $\beta$ subunits respectively. The assay is able to detect only proteins containing both subunits and can be performed with unpurified crude cell extracts. The developed method was optimized by using an experimental design approach, evaluated by measuring the levels of recombinant C-P4H produced in E. coli cells and applied in optimization of recombinant C-P4H production in E. coli.

\section{Results}

\section{Method development}

The principle of the method is drawn in figure 1. At first the $\mathrm{C}-\mathrm{P} 4 \mathrm{H}$ binds to capture antibodies coupled with magnetic beads. The monoclonal antibodies against the $\alpha$ subunit (mab- $\alpha$ ) were chosen for protein capturing to avoid the system blocking with abundant free PDI $\beta$ subunits. The amount of free PDI/ $\beta$ subunits in $\mathrm{C}-\mathrm{P} 4 \mathrm{H}$ producing $E$. coli cells is high since the production starts with $\mathrm{PDI} / \beta$ subunits expression to keep the later expressed $\alpha$ subunits in a soluble form [14]. After the binding step the complex is washed and incubated with detection antibodies. The protein detection with polyclonal antibody against another $\mathrm{C}-\mathrm{P} 4 \mathrm{H}$ subunit $(\mathrm{PDI} / \beta)$ guarantees that only proteins containing both $\alpha$ and $\mathrm{PDI} / \beta$ subunits will be measured. Goat Anti-Rabbit IgG labeled with alkaline phosphatase (GAR-AP) attaches to the detection antibody, and the alkaline phosphatase catalyzes substrate transformation reactions with fluorescent products generation. The fluorescence signal is proportional to the $\mathrm{C}$ $\mathrm{P} 4 \mathrm{H}$ concentration.

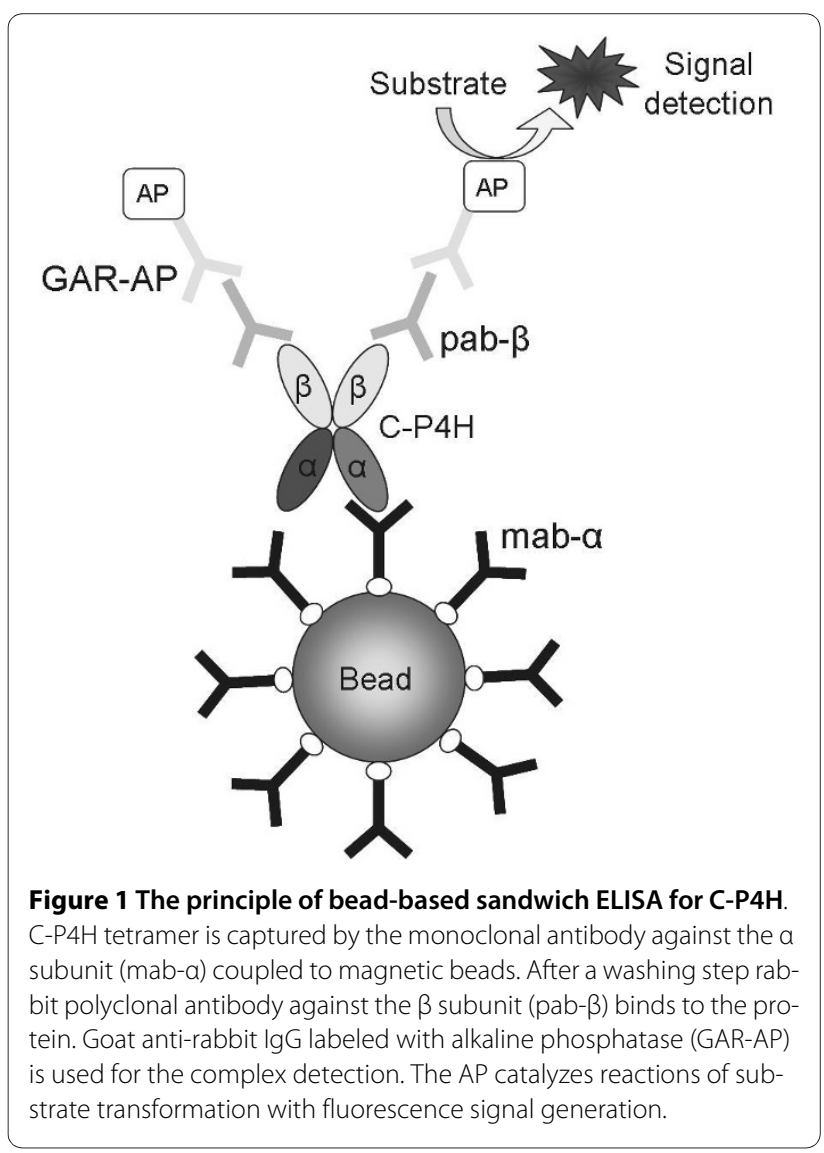




\section{Mab- $\alpha$ attachment to magnetic beads}

The mab- $\alpha$ labeling with biotin molecules and their attachment onto the streptavidin bead surface were tested (Figure 2A). Therefore streptavidin coated magnetic beads were incubated with different amounts of the biotinylated mab- $\alpha$. The antibody attached to the beads via the biotin-streptavidin interaction. The formed complex was washed and detected with the Goat Anti-Mouse IgG labeled with alkaline phosphatase (GAM-AP).

Different mab- $\alpha$ and GAM-AP antibodies concentrations were used in the experiment. Generated fluorescent signals proved to be close to the maximum ones ever observed for the bead-based fluorescent assay irrespective of the antibodies dilutions (data not shown). Background fluorescence obtained without adding mab- $\alpha$ was 20-140 times lower compared to specific signals. The best relation between the signal and background (FLU Signal/ background ratio) was achieved with the most diluted mab- $\alpha$ (dilution 1/500) and GAM-AP (dilution 1/2500) (Figure 2B) since the background fluorescence grew with increasing of the antibodies concentrations. It was decided to select the exact optimal antibodies concentrations in the sandwich ELISA using the C-P4H tetramer as a target. $1 / 500$ dilution of the mab- $\alpha$ and $1 / 2500$ dilution for the secondary detection antibody were chosen for further experiments.

\section{Choosing the optimal pab- $\beta$}

Four different polyclonal antibodies against human PDI were tested as the C-P4H sandwich ELISA detection antibody (Figure 3). 1, 10 and 20 ng of purified C-P4H were used as a target. The antibodies dilutions were as follows: $1 / 500$ for mab- $\alpha$ and for each pab- $\beta$, and $1 / 5000$ for GARAP used here as a secondary detection antibody. The secondary antibody (GAR-AP) concentration was chosen lower than for the GAM-AP antibody used in the previous experiment since the less amount of detectable complexes were expected here.
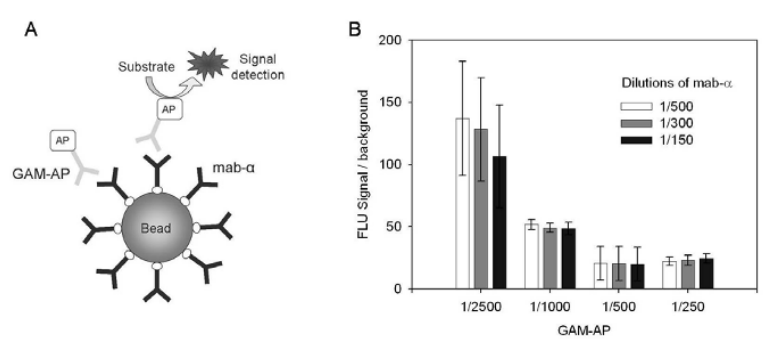

Figure 2 Attachment of mab-a to magnetic beads and influence of mab- $a$ and GAM-AP dilutions on fluorescent signal. (A) The principle of the test. The mab-a binds to magnetic beads via biotin-streptavidin interaction. The complex is detected with the Goat Anti-Mouse IgG labeled with AP (GAM-AP). (B) The generated signals obtained when different mab- $a$ and GAM-AP concentrations were used. The error bars show the \pm SD of three parallel experiments.

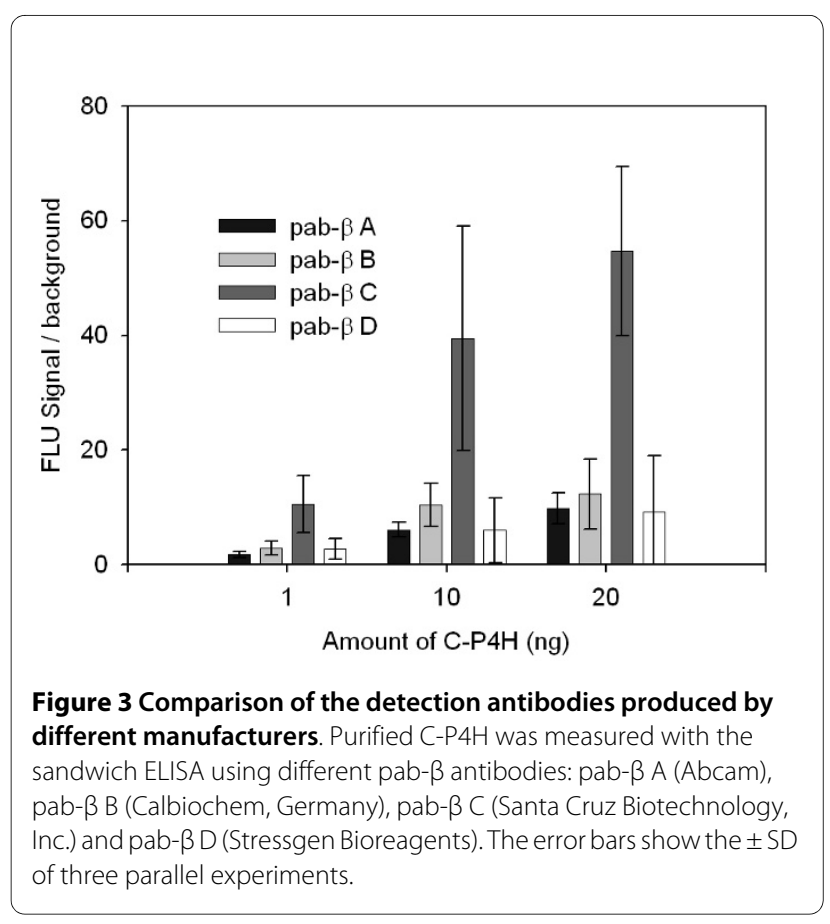

The signal/background ratios were compared for each pab- $\beta$. This parameter was about 3 times higher when pab- $\beta C$ was used; therefore this antibody was selected for further experiments.

A big variability observed for the results was due to clumping of the beads in some experiments. To avoid this effect, increase the efficiency of the washing and the sensitivity of the assay, the method was optimized in the followed experiment.

\section{Optimization of the method}

The influence of different parameters (hybridization time, salt concentration in the washing buffer and shaking rate) was studied to optimize the sensitivity, accuracy and reproducibility of the assay (Figure 4). The responses were presented as absolute signal minus background signal instead of signal to background ratio used earlier in order to visualize better the effect of the changed parameters. The highest fluorescent signal compared to the background level and the lowest standard deviation were obtained when the protein was incubated with each antibody for $1 \mathrm{~h}$. Although a longer hybridization (more than $1 \mathrm{~h}$ ) could positively effect on the signal, it was not tested, since it would noticeably increase the total assay time. The shaking rate during the hybridization step did not significantly influence the results (Figure 4A), and 700 rpm shaking rate was selected because it prevents sedimentation of the beads. An elevated concentration of $\mathrm{NaCl}$ in the washing buffer was expected to increase washing efficiency, but it did not have a significant effect on the signal (Figure 4B). It was obvious that plates need 


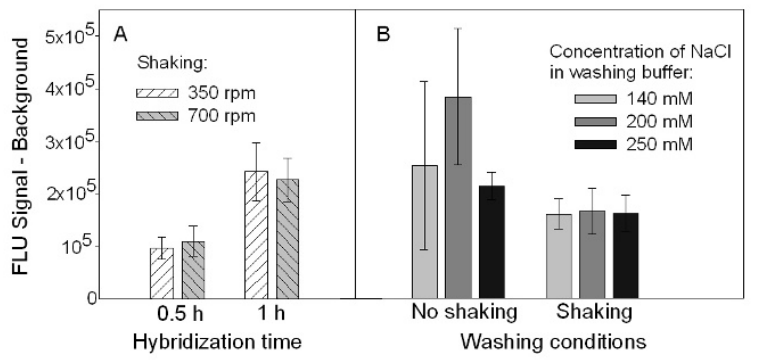

Figure 4 Optimization of hybridization and washing procedures of the C-P4H sandwich ELISA. (A) Optimization of the hybridization time. (B) Optimization of the washing conditions (shaking rate and $\mathrm{NaCl}$ concentration in the washing buffer). $1 \mathrm{ng}$ of purified C-P4H was used as target. The error bars show the \pm SD of three parallel experiments.

to be shaken during the washing phases between the hybridization steps. Without shaking the beads clumped and the washing was not efficient enough causing increased variation between the replicates (Figure 4B).

\section{Optimization of the antibody concentrations}

The concentrations of the antibodies used in the sandwich ELISA were optimized using an experimental design approach.

The full factorial design of response surface methodology (RSM) was chosen to explore the optimal level of the three antibodies (Table 1). FLU signal/background ratio was measured with the sandwich ELISA for 1, 20 and 50 ng of C-P4H and used as the response (Additional file 1, table S1). The data was fitted with multiple regression to a second-order polynomial model equation using MODDE 8 software.

The analysis of variance (ANOVA) was applied to test the fit of the model equation significance. The importance of each variable and their interactions were evaluated using P-values. P-values less than 0.05 indicate that model terms are significant ( $5 \%$ significance level). In the case of measuring $1 \mathrm{ng}$ of $\mathrm{C}-\mathrm{P} 4 \mathrm{H}$, coded values of each antibody dilution, interaction between mab- $\alpha$ and GARAP dilutions and pab- $\beta$ dilution quadratic coded value are significant model terms (Additional file 2, table S2). The model statistical significance was checked by F-tests

Table 1: Coded values for antibody concentrations

\begin{tabular}{clll}
\hline Coded values & \multicolumn{3}{l}{ Antibody dilutions } \\
& mab-a & pab- $\boldsymbol{\beta}$ & GAR-AP \\
& & & \\
\hline-1 & $1 / 1000$ & $1 / 1000$ & $1 / 10000$ \\
0 & $1 / 500$ & $1 / 500$ & $1 / 5000$ \\
1 & $1 / 250$ & $1 / 250$ & $1 / 2500$ \\
\hline
\end{tabular}

(Additional file 3, table S3). The first F-test, comparing modellable and unmodellable variance, was satisfied since its P-value was $<0.05$. The second, lack of fit, test, comparing the model and the replicate errors with each other, was also satisfied since its $\mathrm{P}$-value was $>0.05$. In addition, the model was evaluated using other statistical parameters showing that the model is good (Additional file 3, table S3).

The models created on the basis of signal/background ratio for 20 and $50 \mathrm{ng}$ of $\mathrm{C}-\mathrm{P} 4 \mathrm{H}$ had similar parameters with the presented model for $1 \mathrm{ng}$ of $\mathrm{C}-\mathrm{P} 4 \mathrm{H}$ (data not shown).

Using the MODDE 8 software optimizer tool the best antibodies concentrations were chosen (Table 2). The model indicates that the mab- $\alpha$ antibody concentration is the most important parameter and it has to be set at the highest level. Most probably, it is possible to get a better response using an even less diluted antibody, but it has not been done because the mab- $\alpha$ antibody is the most expensive reagent of the assay. To reduce the method significantly, the fourth parameter, mab- $\alpha$ antibody cost, was included in the optimizer. After this correction, the following antibodies dilutions were selected: $1 / 500$ for mab- $\alpha, 1 / 700$ for pab- $\beta$ and $1 / 3000$ for GAR-AP.

The response surface plot shown in figure 5 illustrates the influence of the parameters pab- $\beta$ and GAR-AP on the signal to background ratio. This plot was obtained for parameter mab- $\alpha$ which was fixed at the dilution $1 / 500$. Finally the test was performed using the selected antibodies dilutions, and the results were shown to be close to predicted values of signal to background ratio (Figure 6).

\section{Sensitivity and range}

The assay sensitivity level and the range were determined using 0 - $40 \mathrm{ng}$ of purified C-P4H tetramer (Figure 7). To simulate the natural background, $1 \mu \mathrm{g}$ of $E$. coli whole cell extract was added to each sample. The detection limit was estimated to be $0.1 \mathrm{ng}$ of C-P4H. This number corresponds to signal which is above the average of the background signal for three times of the blank signal standard deviation. The dependence observed between the C-P4H amount and the fluorescent signal can be used for C-P4H concentration estimation in real samples. The response was presented as the absolute signal minus the background signal in order to be able to estimate protein amount in samples more precisely.

\section{Analysis of the recombinant C-P4H expression in Escherichia coli}

The effect of biological material on the signal of the sandwich ELISA was studied by measuring the amount of $\mathrm{C}$ $\mathrm{P} 4 \mathrm{H}$ in different dilutions of cell extracts of $E$. coli cells expressing C-P4H (0.5 - $10 \mu \mathrm{g}$ of total proteins). The cells expressing $\mathrm{C}-\mathrm{P} 4 \mathrm{H}$ were cultivated and disrupted as 


\begin{tabular}{|c|c|c|c|c|}
\hline \multirow[t]{2}{*}{ Amount of C-P4H, ng } & \multirow[t]{2}{*}{ FLU signal/background } & \multicolumn{3}{|c|}{ Dilutions of antibody } \\
\hline & & mab-a & pab- $\beta$ & GAR-AP \\
\hline 1 & 13.37 & $1 / 250$ & $1 / 770$ & $1 / 2500$ \\
\hline 20 & 75.78 & $1 / 250$ & $1 / 710$ & $1 / 2500$ \\
\hline 50 & 88.77 & $1 / 250$ & $1 / 830$ & $1 / 3300$ \\
\hline
\end{tabular}

explained in the Methods, diluted with the main buffer and used as a target for the sandwich ELISA in amount of $10 \mu \mathrm{L}$, corresponded to $0.5-10 \mu \mathrm{g}$ of total proteins. The inhibition effect was observed with increasing of the total proteins concentration in the samples (Figure 8). To minimize this effect, the amount of total cell proteins analyzed with the assay should not exceed $1 \mu \mathrm{g}$.

The results obtained with the sandwich ELISA for C$\mathrm{P} 4 \mathrm{H}$ were compared with an activity assay based on the formation of 4 -hydroxy $\left[{ }^{14} \mathrm{C}\right]$ proline in a $\left[{ }^{14} \mathrm{C}\right]$ prolinelabeled substrate consisting of nonhydroxylated procollagen polypeptide chains [17]. The activity of 10 crude samples of $\mathrm{C}-\mathrm{P} 4 \mathrm{H}$ produced in E. coli was measured. The same samples were analyzed with the sandwich ELISA for $\mathrm{C}-\mathrm{P} 4 \mathrm{H}$ and the results were compared as shown in figure 9. A linear function and correlation coefficient of $\mathrm{R}^{2}=$ 0.986 were observed demonstrating high correlation between the two methods. The observed correlation is valid only for the performed experiments, since the correlation between specific activity and amount of enzyme

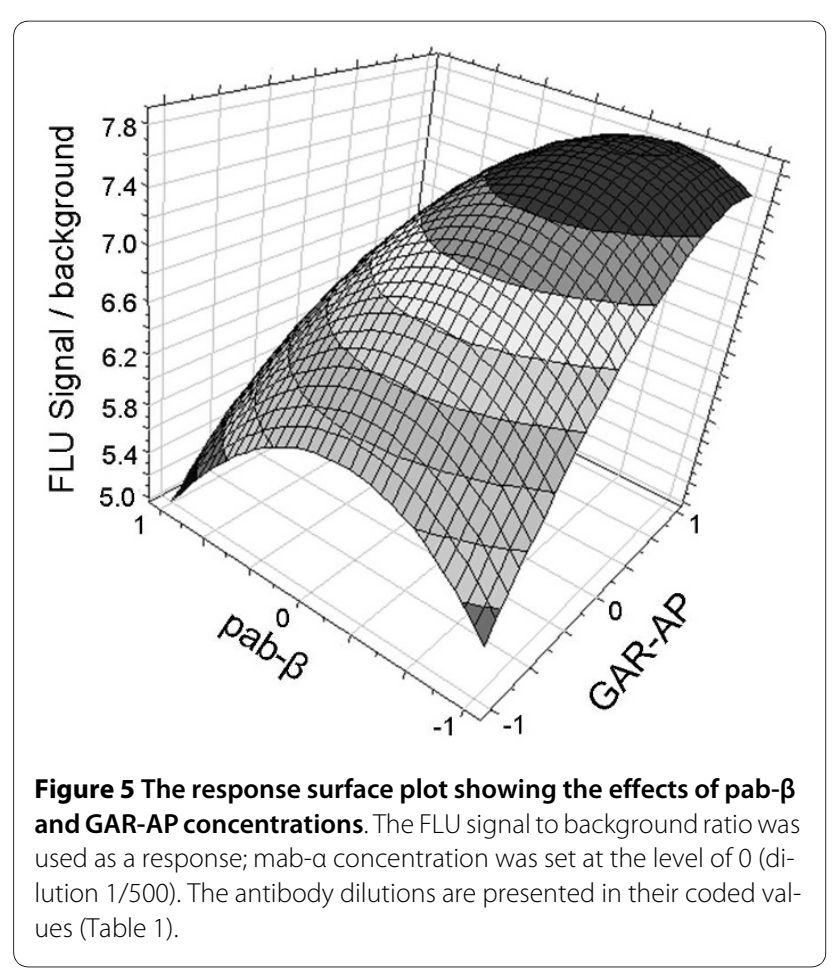

maybe different under different conditions such as expression levels, cell lysis or production conditions.

\section{Optimization of a fed-batch fermentation process for $\mathrm{C}-\mathrm{P} 4 \mathrm{H}$ production in Escherichia coli}

The developed method was used in optimization of a fedbatch fermentation process of recombinant $\mathrm{C}-\mathrm{P} 4 \mathrm{H}$ production by $E$. coli. The experiment aimed at evaluating the effect of a lowered oxygen transfer rate after the first induction (IPTG) and the influence of the cell density at the first induction time on the produced enzyme amount. It was proposed that a lower oxygen transfer rate might exhibit a positive influence on the recombinant C-P4H expression by $E$. coli. In contrast to shake flask cultures where anhydrotetracyclin (aTc) caused a long-term $\alpha$ subunit induction, aTc induction was only transient in bioreactor cultures with strong aeration, possibly by an oxidation and thereby inactivation of the inducer aTc [20]. Furthermore, the production host for C-P4H was the $E$. coli Origami, a double mutant $(\operatorname{tr} x B$ gor), which also might benefit from lower culture oxygenation. This

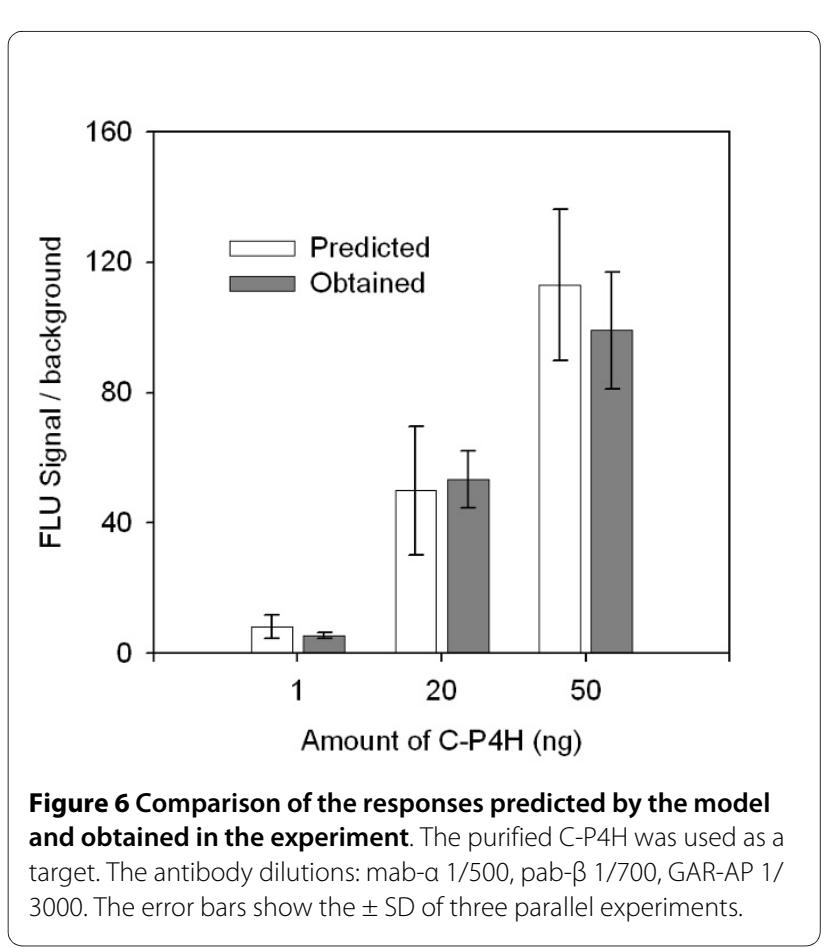




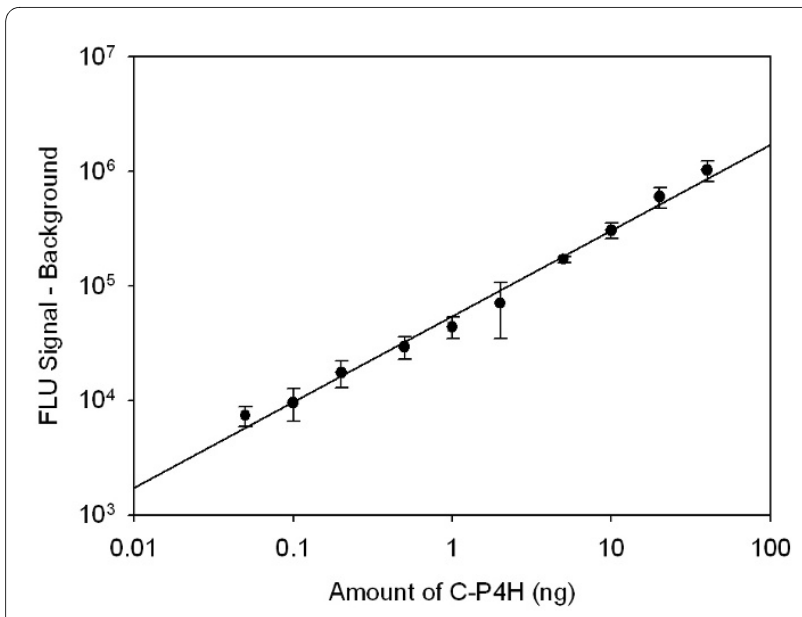

Figure 7 Standard curve of the bead-based sandwich ELISA for CP4H. 0 - 40 ng of purified C-P4H were used as a target. The error bars show the \pm SD of three parallel experiments

mutant is heavily disturbed in the cytoplasmic redox system and only grows reasonably if combined with a suppressor mutation in the $\operatorname{ahpC}$ gene. However these strains show a high constitutive expression of the transcriptional regulator of the oxidative stress response, OxyR [21]. Therefore, based on the comparison of earlier results for cell growth and $\mathrm{C}-\mathrm{P} 4 \mathrm{H}$ overexpression in shake flasks and in bioreactors with a very much higher

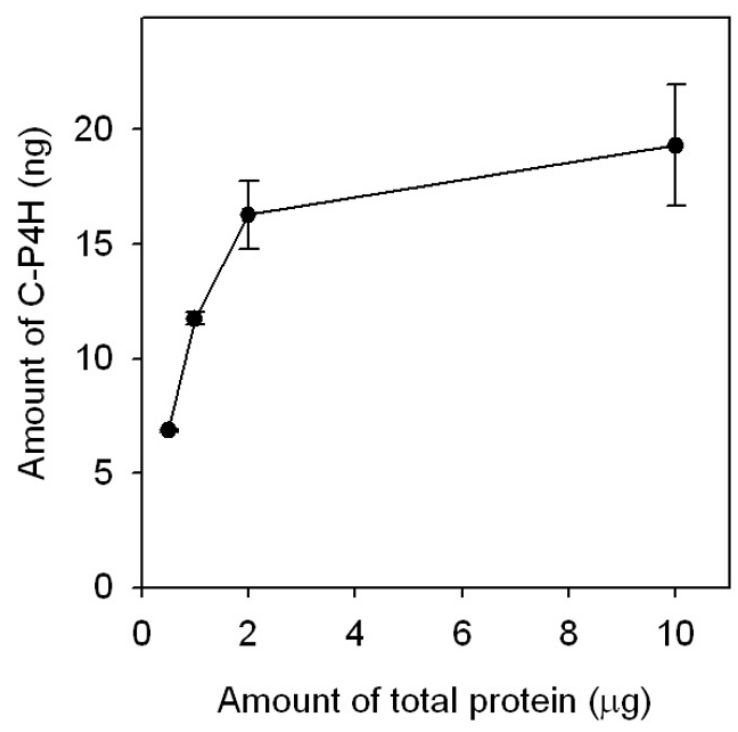

Figure 8 The effect of cell lysate on the signal of the sandwich ELISA. The amount of the C-P4H was measured in $0.5-10 \mu \mathrm{g}$ of extract of E. colicells expressing C-P4H. The error bars show the \pm SD of three parallel experiments.

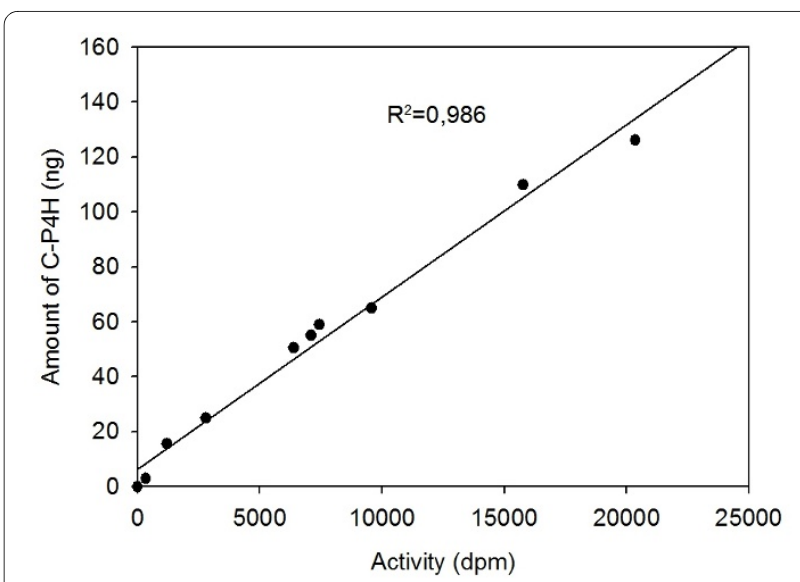

Figure 9 Correlation between the C-P4H activity detected with the radioactive assay and the $\mathrm{C}-\mathrm{P} 4 \mathrm{H}$ amount measured with the bead-based sandwich ELISA. The plotted amounts of C-P4H and activity units were presented per $10 \mu \mathrm{g}$ of total E. coli protein.

oxygen transfer rate, we have earlier suggested that a low oxygenation level may decrease this oxidative stress [16].

In order to avoid laborious cultivations in bioreactor the fed-batch conditions were performed in shake flasks using a glucose auto-delivery system (EnBase ${ }^{\circ}$ ) which simulates the conditions of a glucose limited fed-batch with constant glucose supply rate [22].

The high value for the shaking rate was chosen to be $220 \mathrm{rpm}$ as in the earlier experiments. The low value was set to $100 \mathrm{rpm}$ after the first induction in order to create a significant change in comparison to the high value without causing a shift to anaerobic metabolism or a shock due to extreme oxygen limitation. The shaking rate before the inductions was kept at $220 \mathrm{rpm}$ in the each experiment.

The induction with IPTG was performed either at an $\mathrm{OD}_{600}$ of approximately 3 or at $\mathrm{OD}_{600}=10$. The cultivation conditions for the experiments are summarized in table 3. Each combination of parameter values was repeated once.

The cell growth of the cultures is shown on figure 10 . The higher oxygen transfer led to a prolongation of the exponential phase which was followed by a temporary growth decrease. Induction at $\mathrm{OD}_{600}=10$ led to final cell densities that were on an average $40 \%$ higher than the values achieved by earlier induction.

The C-P4H production was monitored at 5.5, 12.5 and $24.5 \mathrm{~h}$ after the first induction using the developed ELISA (Figure 11). The experiments with high shaking rate and early induction showed the lowest product yield, slightly increasing over time (black bars). Induction with IPTG at an $\mathrm{OD}_{600}$ of 10 instead of 3 increased the protein production considerably (dark grey bars). With this combination of parameters (high shaking rate and late induction), the 
Table 3: Optimization of C-P4H production: summary of cultivation conditions

\begin{tabular}{cc}
\hline shaking rate [rpm] & 1st induction at OD600 = \\
\hline 220 (high level) & 3 (low level) \\
220 (high level) & 10 (high level) \\
220,100 after $1^{\text {st induction }}$ & 3 (low level) \\
$\begin{array}{c}\text { (low level) } \\
220,100 \text { after } 1^{\text {st }} \text { induction } \\
\text { (low level) }\end{array}$ & 10 (high level) \\
\hline
\end{tabular}

highest values after $12.5 \mathrm{~h}$ in relation to the culture volume were achieved (lower part of figure 11). The cultivations with reduced shaking rate after carrying out the first induction at $\mathrm{OD}_{600}=3$ resulted in the highest overall product yield relating to the total cell protein amount (light grey bars, upper part of figure 11). When the first induction was performed at high level $\left(\mathrm{OD}_{600}=10\right)$ and the shaking rate lowered to $100 \mathrm{rpm}$ subsequently, the second lowest product yield in comparison to the other experiments was obtained (white bars). There was a linear increase of $\mathrm{C}-\mathrm{P} 4 \mathrm{H}$ expression per total protein over the cultivation time.

The significance of the factors (shaking rate and induction time) was evaluated statistically using MODDE 8 software (Table 4). A positive factor effect means that the changing of the factor value leads to significant response changes. It is obvious that the factors were dependent of each other since there was always an interaction between the variables. Furthermore, the continuous shaking rate of $220 \mathrm{rpm}$ had a negative influence on the protein pro-

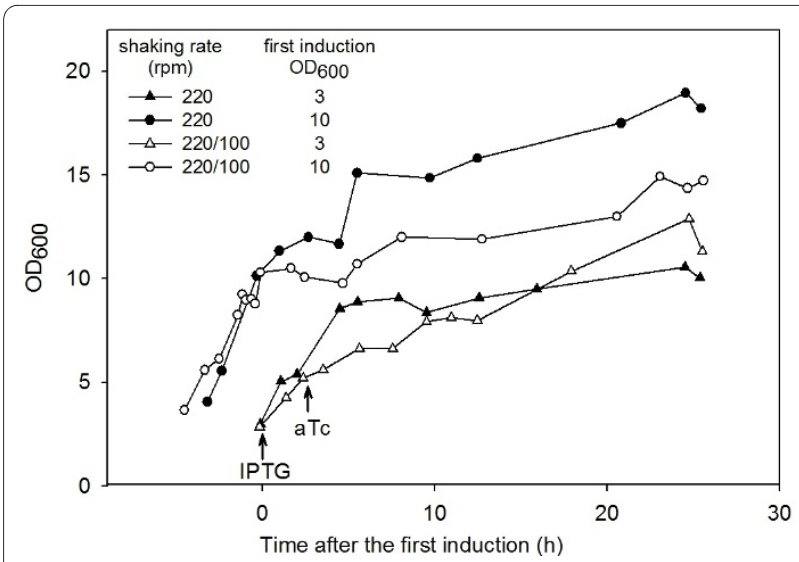

Figure 10 The growth of $E$. coli produced recombinant C-P4H under different cultivation conditions. The cells were cultivated with using EnBase technology, varying shaking rate and induction time. The arrows indicate the inductions of the PDI/ $\beta$ and a subunits expression with IPTG and aTc, respectively

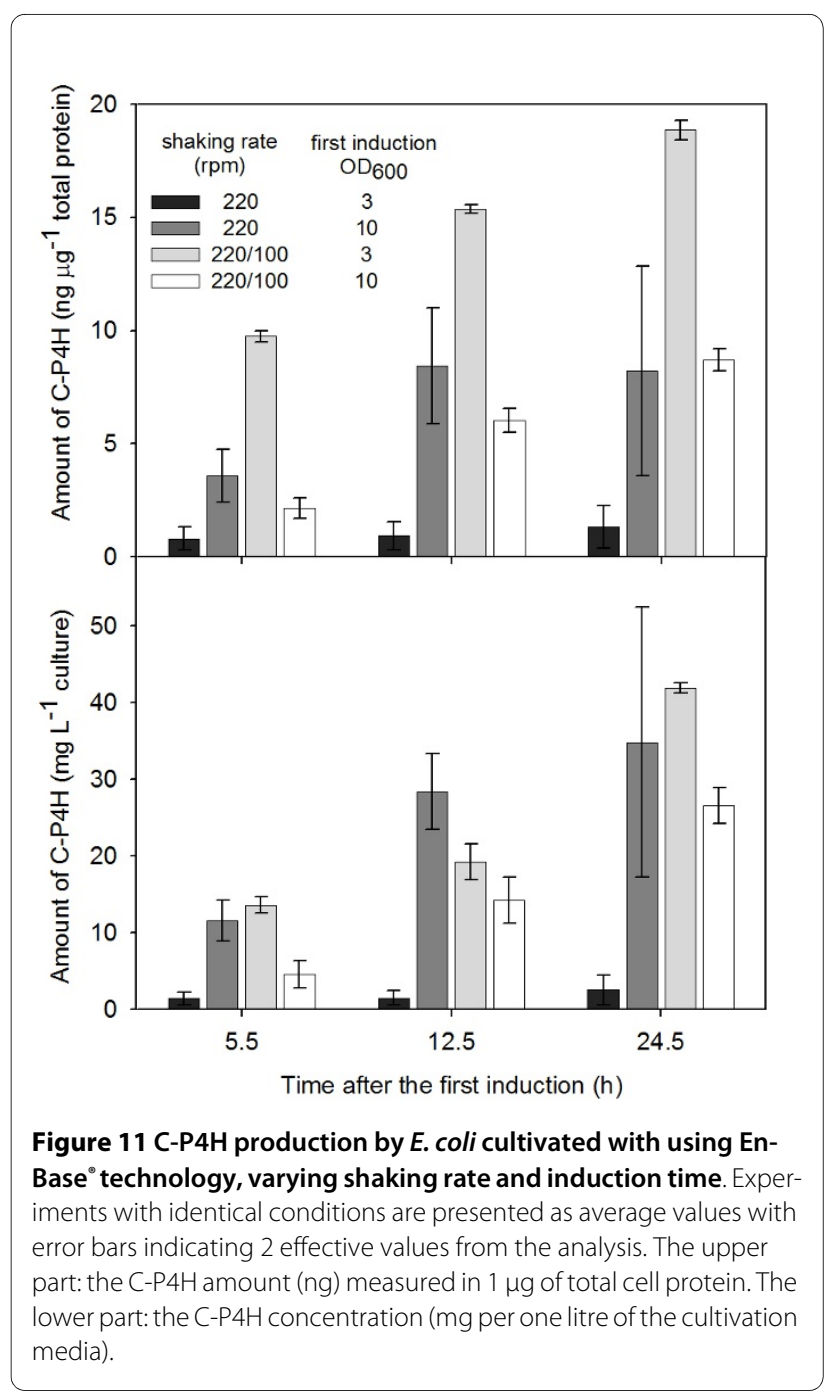

duction per cell at all sampling times. The effect induction time was not evident in the most of cases.

\section{Discussion}

A method for quantitative C-P4H holoenzyme detection in crude cell extracts was developed for monitoring of recombinant $\mathrm{C}-\mathrm{P} 4 \mathrm{H}$ production. $\mathrm{C}-\mathrm{P} 4 \mathrm{H}$ coexpression is required for production of recombinant collagens at that the enzyme's activity is a critical parameter [8,9,11-14]. Therefore C-P4H concentration monitoring of becomes important for the quality control in recombinant collagen processes. The $\alpha$ subunit of the enzyme has a high aggregation tendency, which may cause low amounts of functional enzyme and consequently low quality of the produced collagen, i.e. temperature instability. The standard test for $\mathrm{C}-\mathrm{P} 4 \mathrm{H}$ activity monitoring is measuring hydroxylation of peptides with radioactive substrate.

When used with other antibodies the here developed method can be principally adapted for the quantification of other protein complexes such as multimeric enzymes, 
Table 4: Effect of shaking rate and $O D_{600}$ at the first induction on C-P4H production

\begin{tabular}{|c|c|c|c|}
\hline & \multicolumn{3}{|c|}{ C-P4H (ng $\mu \mathrm{g}-1$ total protein) } \\
\hline & 5.5 & 12.5 & 24.5 \\
\hline Shaking rate & - & - & - \\
\hline $\mathrm{OD}_{600}$ at the fist induction & - & $(-)$ & $(-)$ \\
\hline \multirow[t]{3}{*}{ interaction } & yes & yes & yes \\
\hline & \multicolumn{3}{|c|}{$\mathrm{C}-\mathrm{P} 4 \mathrm{H}\left(\mathrm{mg} \mathrm{L}^{-1}\right)$} \\
\hline & 5.5 & 12.5 & 24.5 \\
\hline Shaking rate & $(-)$ & $(-)$ & $(-)$ \\
\hline $\mathrm{OD}_{600}$ at the fist induction & $(-)$ & + & $(+)$ \\
\hline interaction & yes & yes & (yes) \\
\hline
\end{tabular}

- negative effect of high level parameter

+ positive effect of high level parameter

() effect is not significant, tendency is shown in parentheses

yes interaction exists

receptors, ion channels etc., in crude or impure samples. The limitations of the required antibodies availability can be evaded in future due to the resource gained within the human protein atlas project [23].

The developed assay is a sandwich ELISA based on C$\mathrm{P} 4 \mathrm{H}$ tetramer hybridization with a biotin labeled capture antibody against its $\alpha$ subunit and a detection antibody against the PDI $\beta$ subunit. The antibodies specificity against the different $\mathrm{C}-\mathrm{P} 4 \mathrm{H}$ subunits ensures entire holoenzyme detection. During the assay the C-P4H is captured through its $\alpha$ subunit and all other molecules including the free PDI $\beta$ subunit are washed away. As a rule, tested samples contain abundance of PDI since it is initially transcribed during the protein expression [14] and it is also presented in excess amounts in relation to the $\alpha$ subunit in vivo.

An experimental design approach applied for the optimal antibodies concentration selection is presented in this study. A full factorial design was chosen because of the possible interactions between the parameters. The model obtained was tested by ANOVA and it proved to be statistically significant. The model indicated that the capture antibody concentration is the most effective parameter, which had to be set at its maximum level. This means that better results could be observed using the less diluted capture antibody, but taking into consideration its high cost $1 / 500$ mab- $\alpha$ dilution was used. For the other antibodies the optimal levels were selected by the model and illustrated as a peak on the response surface plot (Figure 5). The signal/background values predicted by the model correlated well with the values which were obtained in a real assay (Figure 6).
The sandwich ELISA sensitivity was determined to be approximately $0.1 \mathrm{ng}$ of $\mathrm{C}-\mathrm{P} 4 \mathrm{H}$ and the assay ranged between 0 and $40 \mathrm{ng}$ of the pure protein.

A high amount of $E$. coli cell proteins had a negative effect on the signals obtained with the sandwich ELISA. This could be caused by antibodies blocking with cell proteins or aggregates of the $\mathrm{C}-\mathrm{P} 4 \mathrm{H} \alpha$ and $\beta$ subunits. To minimize this effect the amount of the total cell protein used for one measurement should not exceed $1 \mu \mathrm{g}$.

The developed sandwich ELISA was compared to the current standard, a radioactive assay which was mainly used for monitoring of the recombinant $\mathrm{C}-\mathrm{P} 4 \mathrm{H}$ assembly and activity during its production in different expression systems [17]. The measured concentrations of the C-P4H produced by $E$. coli cells correlated well with the amount of the enzyme activity (Figure 9). Therefore, as the sandwich ELISA is a quantitative and simple method for C$\mathrm{P} 4 \mathrm{H}$ measuring in crude samples, it is very suitable for high-throughput analyses instead of the technically demanding and time consuming radioactive assay.

The sandwich ELISA was applied for C-P4H level measuring in experiments aimed at optimizing of the C-P4H production by $E$. coli cells. The highest specific yield of active recombinant C-P4H up to now in cultivation with the Origami strain has been reported by Neubauer et al. [16]. Using the EnBase glucose auto-delivery system [22] we were able to obtain fed-batch conditions in shake flasks and succeeded to produce a high level of C-P4H tetramer in the shake flask scale (maximum product yield per culture volume was $42.5 \mathrm{mg} \mathrm{L}^{-1}$ ). It was shown that the oxygen transfer rate, the time for the first inducer (IPTG) addition and the interaction between these factors have a significant influence on the $\mathrm{C}-\mathrm{P} 4 \mathrm{H}$ production. In this study the maximum product yield was obtained under the following conditions: when the first induction (with IPTG) was performed at an $\mathrm{OD}_{600}$ of 3 and the oxygen transfer rate was reduced after the induction. These results may be treated as indirect proof for the supposition that the inducer aTc can be inactivated by a good oxygenation of the cultivation medium. Although not in the focus of the article, we propose that cultivations performed with aTc should be carried out under oxygen limitation.

A commercially available immunoassay for the serum $\mathrm{C}-\mathrm{P} 4 \mathrm{H}$ detection utilizes only antibodies specific for the $\mathrm{PDI} / \beta$ subunit and thus detects also free $\mathrm{PDI} / \beta$-subunits [19]. As PDI is a common and copious enzyme in the endoplasmic reticulum, this method fails to analyze the C-P4H amount or activity. In the method developed here only the C-P4H tetramers are measured due to the fact that antibodies against both subunits are used for the protein capturing and detection. The described sandwich ELISA has a potential to be a tool for the assembled C$\mathrm{P} 4 \mathrm{H}$ quantification in blood at fibrotic diseases detection. 


\section{Conclusions}

The method developed in this study is relevant to quantitative collagen prolyl-4-hydroxylase detection for monitoring the recombinant $\mathrm{C}-\mathrm{P} 4 \mathrm{H}$ production and $\mathrm{C}-\mathrm{P} 4 \mathrm{H}$ coexpression during recombinant collagens production. The specificity of the antibodies used in the assay against the different collagen prolyl-4-hydroxylase subunits ensures detection of the holoenzyme only, but not its separate subunits. Using an experimental design approach the antibody concentrations in the ELISA were optimized. The method was successfully applied for monitoring the recombinant $\mathrm{C}-\mathrm{P} 4 \mathrm{H}$ amount in crude cell extracts of $E$. coli during the optimization of C-P4H production. This study demonstrates the sandwich ELISA applicability for quantifying of proteins consisting of different subunits in crude samples. The method is potential for recombinant multimeric proteins production monitoring as well as complex proteins detection in clinical and food diagnostics.

\section{Methods}

\section{Strain and cultivation conditions}

For production of recombinant C-P4H the strain E. coli Origami $^{\text {mix }}(\Delta$ (ara-leu) 7697 araD139 $\Delta$ lacX74 aphC galE galK rpsL $\triangle$ phoA PvuII phoR F[lac (lacIq)pro] gor522:: $\operatorname{Tn} 10\left(\mathrm{Tc}^{\mathrm{R}}\right) \operatorname{tr} x B:: k a n$, Novagen) carrying a vector for cytoplasmic expression of recombinant $\mathrm{C}-\mathrm{P} 4 \mathrm{H}$ (pP4Hcyt) was used [16]. Shake flask cultivations were performed in a modified LB medium containing $20 \mathrm{~g} \mathrm{~L}^{-1}$ tryptone, $10 \mathrm{~g} \mathrm{~L}^{-1}$ yeast extract, $5 \mathrm{~g} \mathrm{~L}^{-1} \mathrm{NaCl}$ and $100 \mathrm{mg}$ $\mathrm{L}^{-1}$ ampicillin. Exponentially grown $10 \mathrm{~mL}$ precultures inoculated with glycerol stocks carried out in $100 \mathrm{~mL}$ Erlenmeyer flasks at $37^{\circ} \mathrm{C}$ and $220 \mathrm{rpm}$ on a rotary shaker served as an inoculum for the main cultures, which were performed in 3-baffled $1 \mathrm{~L}$ Erlenmeyer flasks with a liquid volume of $100 \mathrm{~mL}$. The cultivations were carried out on a rotary shaker at $220 \mathrm{rpm}$ and $25^{\circ} \mathrm{C}$ and were set to $20^{\circ} \mathrm{C}$ after the second induction [14]. When the cell density $\left(\mathrm{OD}_{600}\right)$ reached 0.2 , expression of the $\mathrm{PDI} / \beta$ subunit was induced with $50 \mu \mathrm{M}$ isopropyl- $\beta$-d-thiogalactoside (IPTG), and when it reached 0.6, expression of the $\alpha$ subunit was induced with $200 \mu \mathrm{g} \mathrm{L}^{-1}$ anhydrotetracycline hydrochloride (aTc, IBA GmbH).

The cultivations aimed at $\mathrm{C}-\mathrm{P} 4 \mathrm{H}$ production optimization were performed using gel-based EnBase technology (Biosilta Oy, Oulu, Finland). EnBase technology supplies the cell culture continuously with glucose and thus allows glucose limited fed-batch cultivation in a closed system $[22,24]$. Pre-cultures were prepared as described earlier. The cultivations were carried out in 3-baffled $1 \mathrm{~L}$ Erlenmeyer flasks with a liquid volume of $100 \mathrm{~mL}$. The glucose-free medium containing $2.0 \mathrm{~g} \mathrm{~L}^{-1} \mathrm{Na}_{2} \mathrm{SO}_{4}, 2.5 \mathrm{~g} \mathrm{~L}^{-1}$ $\left(\mathrm{NH}_{4}\right)_{2} \mathrm{SO}_{4}, 0.50 \mathrm{~g} \mathrm{~L}^{-1} \mathrm{NH}_{4} \mathrm{Cl}, 14.60 \mathrm{~g} \mathrm{~K}_{2} \mathrm{HPO}_{4}, 3.60 \mathrm{~g} \mathrm{~L}^{-1}$
$\mathrm{NaH}_{2} \mathrm{PO}_{4} \cdot 2 \mathrm{H}_{2} \mathrm{O}, 1.00 \mathrm{~g} \mathrm{~L}^{-1}\left(\mathrm{NH}_{4}\right)_{2}$-H-citrate, $3 \mathrm{mM}$ $\mathrm{MgSO}_{4}, 0.1 \mathrm{~g} \mathrm{~L}^{-1}$ thiamine hydrochloride, $2 \mathrm{ml} \mathrm{L}^{-1}$ trace element solution (containing: $0.50 \mathrm{~g} \mathrm{~L}^{-1} \mathrm{CaCl}_{2} \cdot 2 \mathrm{H}_{2} \mathrm{O}$, $0.18 \mathrm{~g} \mathrm{~L}^{-1} \mathrm{ZnSO}_{4} 7 \mathrm{H}_{2} \mathrm{O}, 0.10 \mathrm{~g} \mathrm{~L}^{-1} \mathrm{MnSO}_{4} \cdot \mathrm{H}_{2} \mathrm{O}, 20.1 \mathrm{~g} \mathrm{~L}^{-1}$ $\mathrm{Na}_{2}$-EDTA, $16.70 \mathrm{~g} \mathrm{~L}^{-1} \mathrm{FeCl}_{3} \cdot 6 \mathrm{H}_{2} \mathrm{O}, 0.16 \mathrm{~g} \mathrm{~L}^{-1} \mathrm{CuSO}_{4}$. $5 \mathrm{H}_{2} \mathrm{O}$ and $\left.0.18 \mathrm{~g} \mathrm{~L}^{-1} \mathrm{CoCl}_{2} \cdot 6 \mathrm{H}_{2} \mathrm{O}\right)$ and $100 \mathrm{mg} \mathrm{L}^{-1}$ ampicillin was used. The expression of the PDI/ $\beta$ subunit was induced with $50 \mu \mathrm{M}$ IPTG with $\mathrm{OD}_{600}$ reached 3 or 10 , and after $2 \mathrm{~h}$ the expression of the $\alpha$ subunit was induced with $200 \mu \mathrm{g} \mathrm{L}-1$ aTc. The cultivation temperature of $25^{\circ} \mathrm{C}$ was lowered to $20^{\circ} \mathrm{C}$ after the $2^{\text {nd }}$ induction. The cultivations were carried out on a rotary shaker at $220 \mathrm{rpm}$. For some cultivations the shaking rate was lowered to 100 rpm after the $1^{\text {st induction. }}$

\section{Analysis of recombinant C-P4H}

Cells were harvested by centrifugation at 20,000 $\times g$ for 5 $\min$ at $4^{\circ} \mathrm{C}$ at different time points before and after the inductions. The size of sample was calculated so that it would contain a quantity cells corresponding to $40 \mathrm{~mL}$ of $\mathrm{OD}_{600}=1$. The pellets were suspended in $2 \mathrm{~mL}$ of the lysis buffer $(0.1 \mathrm{M} \mathrm{NaCl}, 0.1 \mathrm{M}$ glycine, $10 \mu \mathrm{M}$ dithiothreitol, $10 \mathrm{mM}$ Tris- $\mathrm{HCl}, \mathrm{pH}$ 7.8) containing complete EDTAfree protease inhibitor cocktail (Roche). The suspension was sonicated for $4 \times 1 \mathrm{~min}$ at $1 \mathrm{~min}$ intervals on ice (Sonifier cell disruptor B-30, Branson, $3 \mathrm{~mm}$ diameter of sonotrode, output control 5) and centrifuged at 15,000 $\times$ $g$ for $15 \mathrm{~min}$ at $4^{\circ} \mathrm{C}$. Soluble cytoplasmic fractions were collected. Recombinant C-P4H was purified by a procedure consisting of a poly (L-proline) affinity chromatography and anion exchange chromatography on a HiTrap Q sepharose column (Amersham Biosciences; [25]).

C-P4H activity in the E. coli fractions was analysed by a method based on the formation of 4-hydroxy $\left[{ }^{14} \mathrm{C}\right]$ proline in a $\left[{ }^{14} \mathrm{C}\right]$ proline-labelled substrate consisting of nonhydroxylated procollagen polypeptide chains [17]. Protein concentrations were determined with the RC DC Protein Assay Kit (Bio-Rad Laboratories).

\section{Antibodies}

An Anti-Human Prolyl-4-Hydroxylase ( $\alpha$ ) Mouse Monoclonal Antibody, clone 9-47H10 (MP Biomedicals, LLC) was used as the capture antibody (mab- $\alpha$ ) for sandwich ELISA. Rabbit Anti-Human PDI Polyclonal Antibody, Abcam (pab- $\beta$ A), Anti-Protein Disulfide Isomerase Rabbit pAb, Calbiochem, Germany (pab- $\beta$ B), PDI (H-160) polyclonal rabbit antibody, Santa Cruz Biotechnology, Inc. (pab- $\beta$ C) and Rabbit Anti-PDI Polyclonal Antibody, Stressgen Bioreagents (pab- $\beta$ D) were tested as detection antibodies. Alkaline Phosphatase-conjugated AffiniPure Goat Anti-Rabbit IgG (H+L) (GAR-AP) and Phosphatase-conjugated AffiniPure Goat Anti-Mouse IgG 
$(\mathrm{H}+\mathrm{L})$ (GAM-AP), Jackson ImmunoResearch Laboratories, Inc. were used as the secondary detection antibody.

The dilutions of the antibodies were done with the main buffer $\left(1 \times\right.$ PBS $\left(1.8 \mathrm{mM} \quad \mathrm{KH}_{2} \mathrm{PO}_{4}, 10 \mathrm{mM}\right.$ $\mathrm{Na}_{2} \mathrm{HPO}_{4}, 140 \mathrm{mM} \mathrm{NaCl}, 2.7 \mathrm{KCl}, \mathrm{pH}$ 7.4) with 1\% BSA).

The capture antibody (mab- $\alpha$ ) was biotinylated with EZ-Link $^{\mathrm{mm}}$ Sulfo-NHS-LC-Biotin, PIERCE, USA. $13.3 \mu \mathrm{l}$ of the antibody was incubated with $1 \mathrm{ml}$ of $10 \mathrm{mM}$ biotin reagent, diluted in the PBS buffer, at $25^{\circ} \mathrm{C}$ for $1 \mathrm{~h}$. The solution was dialysed using Slide-A-Lyser Mini Dialysis Units (10,000 MWCO), PIERCE, USA, in PBS buffer during $1 \mathrm{~h}$.

\section{Sandwich ELISA (optimized protocol)}

The analysis was carried out in U-shaped transparent 96well microtiter plates (Greiner Bio-One, Frickenhausen, Germany). The wells were incubated with $120 \mu \mathrm{L}$ of the main buffer $\left(1 \times\right.$ PBS $\left(1.8 \mathrm{mM} \quad \mathrm{KH}_{2} \mathrm{PO}_{4}, 10 \mathrm{mM}\right.$ $\mathrm{Na}_{2} \mathrm{HPO}_{4}, 140 \mathrm{mM} \mathrm{NaCl}, 2.7 \mathrm{KCl}, \mathrm{pH}$ 7.4) with 1\% BSA) for $30 \mathrm{~min}$ at $25^{\circ} \mathrm{C}$ and $700 \mathrm{rpm}$ in a Thermomixer comfort (Eppendorf). After the incubation, the buffer was discarded and the plate was allowed to dry. The wells were incubated $\left(30 \mathrm{~min}, 25^{\circ} \mathrm{C}, 700 \mathrm{rpm}\right.$ ) with $85 \mu \mathrm{L}$ of biotinlabeled capture antibody (mab- $\alpha$ ) diluted 1:500 and $15 \mu \mathrm{L}$ of streptavidin coated paramagnetic beads [26,27], previously washed 3 times in the main buffer. Before adding $100 \mu \mathrm{L}$ of the purified protein or samples, the wells were washed once with a washing solution $(1 \times$ PBS containing $1 \%$ BSA and $0.05 \%$ Tween 20 ). The washing solution was incubated in the plate for $1 \mathrm{~min}\left(25^{\circ} \mathrm{C}, 750 \mathrm{rpm}\right)$ and then removed while the magnetic beads were retained in the wells by a magnet. After incubation of the samples $(1 \mathrm{~h}$, $25^{\circ} \mathrm{C}, 700 \mathrm{rpm}$ ), the wells were washed twice, $100 \mu \mathrm{L}$ per well of the first detection antibody (pab- $\beta$ ) diluted 1:700 was added and incubated in the plate $\left(1 \mathrm{~h}, 25^{\circ} \mathrm{C}, 700\right.$ $\mathrm{rpm}) .100 \mu \mathrm{L}$ of the secondary detection antibody (GARAP) diluted 1:3000 was added after 3 more washing steps and incubated $\left(1 \mathrm{~h}, 25^{\circ} \mathrm{C}, 700 \mathrm{rpm}\right)$. After the incubation, the wells were washed 3 times and the liquid from the last washing step was transferred into a new plate together with the beads. The wells of the new plate were washed once more.

In order to obtain a fluorescence signal, $100 \mu \mathrm{L}$ of the AttoPhos (BBTP) substrate was added into each well and the enzymatic reaction was allowed to take place while incubating the plate for $20 \mathrm{~min}\left(37^{\circ} \mathrm{C}, 700 \mathrm{rpm}\right.$, protected from light). The measurement was performed with $90 \mu \mathrm{L}$ of the liquid from each well in a black microtiter plate (OptiPlate ${ }^{\mathrm{mw}}-96 \mathrm{~F}$, PerkinElmer ${ }^{\mathrm{TN}}$ Life Sciences, USA) using a Wallac Victor ${ }^{2} 1420$ Multilabel counter (PerkinElmer ${ }^{\mathrm{TN}}$ Life Sciences, USA) at an excitation wavelength of $430 / 450 \mathrm{~nm}$ and an emission wavelength of $560 \mathrm{~nm}$.

\section{Experimental design and statistical analysis}

A $3^{3}$ full factorial design was used to optimize the antibodies dilutions for C-P4H sandwich ELISA. The center points of the parameters corresponded to previously used concentrations, and double diluted and double concentrated solutions of the antibodies were tested. These concentrations were logarithmically transformed and coded as $0,-1$ and 1 , respectively for statistical calculations (Table 1). The levels of the variables and the experimental design are shown in additional file 1, table S1. In this study, the experiment design contains 60 trials including 3 center points and 1 replicate of each trial. The ratio of fluorescence signal to background obtained for 1, 20 and $50 \mathrm{ng}$ of C-P4H was selected as a response value. The second-order polynomial model was created and analyzed using MODDE 8 software (Umetrics, Sweden).

\section{Additional material}

\section{Additional file $13^{3}$ full factorial design for the antibody concentra- tion optimization. \\ Additional file 2 ANOVA for the antibody concentration model. A parameter is significant if its $P$-value is lower $0.05 . X_{1}, X_{2}$ and $X_{3}$ are coded dilutions of mab- $a$, pab- $\beta$ and GAR-AP antibody, respectively. \\ Additional file 3 The evaluation of the antibody concentration model}

\section{Competing interests}

The authors declare that they have no competing interests.

\section{Authors' contributions}

EO designed the experiments and carried them out for the method development, optimization and testing. AN participated in the method development and performed the experiments for C-P4H production and its detection with the radioactive assay. $\mathrm{KK}$ performed experiments for optimization of $\mathrm{C}-\mathrm{P} 4 \mathrm{H}$ production. JM contributed with ideas and discussions in the design of the experiments and the writing of the manuscript. PN participated in the design and supervision of the work. All authors read and approved the final manuscript.

\section{Acknowledgements}

Dr. Kristian Koski is thanked for providing a purified C-P4H. Dr. Tomi Hillukkala, Galina Bazhenova, Dr. Pekka Belt, Dr. Janne Härkönen and Dr. Matti Möttönen are acknowledged for critical editing of this manuscript. This study was supported by TEKES-NeoBio program and Biocenter Oulu (Finland).

\section{Author Details}

1Bioprocess Engineering Laboratory, Department of Process and Environmental Engineering, P.O.Box 4300, FIN-90014 University of Oulu, Finland , 2Oulu Center for Cell-Matrix Research, Biocenter Oulu and Department of Medical Biochemistry and Molecular Biology, P.O.Box 5000, FIN-90014 University of Oulu, Finland and 3 Laboratory of Bioprocess Engineering, Department of Biotechnology, Technische Universität Berlin, Ackerstr. 71-76, D13355 Berlin, Germany

Received: 31 March 2010 Accepted: 17 June 2010 Published: 17 June 2010

\section{References}

1. Nielsen UB, Geierstanger BH: Multiplexed sandwich assays in microarray format. JImmunol Methods 2004, 290(1-2):107-20.

2. Myllyharju J: Prolyl 4-hydroxylases, key enzymes in the synthesis of collagens and regulation of the response to hypoxia, and their roles as treatment targets. Annals of Medicine 2008, 40:402-417. 
3. Keiser HR, Vogel CL, Sadikali F: Protocollagen proline hydroxylase in sera of Ugandans with hepatocellular carcinoma. J Natl Cancer Inst 1972, 49:1251-1255

4. Fuller GC, Nolan JC: Prolyl hydroxylase activity in normal and diseased human liver. Proc Soc Exp Biol Med 1976, 151:61-64.

5. Tuderman L, Risteli J, Miettinen TA, Kivirikko KI: Serum immunoreactive prolyl hydroxylase in liver disease. Eur J Clin Invest 1977, 7:537-541.

6. Nagai Y, Kato M, Toda G: Selectivity of serum immunoreactive prolyl 4hydroxylase as a marker for hepatic necrosis. J Gastroenterol Hepatol 1992, 7:253-256

7. Vuori K, Pihlajaniemi T, Marttila M, Kivirikko Kl: Characterization of the Human Prolyl 4-Hydroxylase Tetramer and Its Multifunctional Protein Disulfide-Isomerase Subunit Synthesized in A Baculovirus Expression System. Proceedings of the National Academy of Sciences of the United States of America 1992, 89:7467-7470.

8. Lamberg A, Helaakoski T, Myllyharju J, Peltonen S, Notbohm H, Pihlajaniemi T, Kivirikko Kl: Characterization of human type III collagen expressed in a baculovirus system - Production of a protein with a stable triple helix requires coexpression with the two types of recombinant prolyl 4-hydroxylase subunit. Journal of Biological Chemistry 1996, 271:11988-11995.

9. Vuorela A, Myllyharju J, Nissi R, Pihlajaniemi T, Kivirikko Kl: Assembly of human prolyl 4-hydroxylase and type III collagen in the yeast Pichia pastoris: formation of a stable enzyme tetramer requires coexpression with collagen and assembly of a stable collagen requires coexpression with prolyl 4-hydroxylase. Embo Journal 1997, 16:6702-6712.

10. John DCA, Watson R, Kind AJ, Scott AR, Kadler KE, Bulleid NJ: Expression of an engineered form of recombinant procollagen in mouse milk. Nature Biotechnology 1999, 17:385-389.

11. Toman PD, Chisholm G, McMullin H, Gieren LM, Olsen DR, Kovach RJ, Leigh SD, Fong BE, Chang R, Daniels GA, Berg RA, Hitzeman RA: Production of recombinant human type I procollagen trimers using a four-gene expression system in the yeast Saccharomyces cerevisiae. Journal of Biological Chemistry 2000, 275:23303-23309.

12. Merle C, Perret S, Lacour T, Jonval V, Hudaverdian S, Garrone R, Ruggiero F, Theisen M: Hydroxylated human homotrimeric collagen I in Agrobacterium tumefaciens-mediated transient expression and in transgenic tobacco plant. FEBS Lett 2002, 515:114-118.

13. Pakkanen $\mathrm{O}$, Hamalainen ER, Kivirikko Kl, Myllyharju J: Assembly of stable human type I and III collagen molecules from hydroxylated recombinant chains in the yeast Pichia pastoris - Effect of an engineered C-terminal oligomerization domain foldon. Journal of Biological Chemistry 2003, 278:32478-32483.

14. Neubauer A, Neubauer P, Myllyharju J: High-level production of human collagen prolyl 4-hydroxylase in Escherichia coli. Matrix Biology 2005, 24:59-68.

15. Kersteen EA, Higgin JJ, Raines RT: Production of human prolyl 4hydroxylase in Escherichia coli. Protein Expr Purif 2004, 38:279-291.

16. Neubauer A, Soini J, Bollok M, Zenker M, Sandqvist J, Myllyharju J, Neubauer P: Fermentation process for tetrameric human collagen prolyl 4-hydroxylase in Escherichia coli: Improvement by gene optimisation of the PDI/beta subunit and repeated addition of the inducer anhydrotetracycline. Journal of Biotechnology 2007 128:308-321.

17. Kivirikko Kl, Myllyla R: Posttranslational enzymes in the biosynthesis of collagen: intracellular enzymes. Methods Enzymol 1982, 82(Pt A):245-304

18. Gorres KL, Raines RT: Direct and continuous assay for prolyl 4hydroxylase. Analytical Biochemistry 2009, 386:181-185.

19. Yoshida S, Bai Y, Muragaki Y, Ooshima A, Inada K, Nagai Y, Obata K, Iwata K, Hashida S, Ishikawa E: A sandwich immunoassay for human prolyl 4hydroxylase using monoclonal antibody. Clin Chim Acta 1986, 160:37-46.

20. Neubauer A: Expression and analysis of recombinant human collagen prolyl 4-hydroxylase in E. coli and optimization of expression. In PhD thesis Oulu University, Department of Medical Biochemistry and Molecular Biology; 2006.

21. Bessette PH, Aslund F, Beckwith J, Georgiou G: Efficient folding of proteins with multiple disulfide bonds in the Escherichia coli cytoplasm. Proc Natl Acad Sci USA 1999, 96(24):13703-8.

22. Panula-Perala J, Siurkus J, Vasala A, Wilmanowski R, Casteleijn MG, Neubauer P: Enzyme controlled glucose auto-delivery for high cell density cultivations in microplates and shake flasks. Microbial Cell Factories 2008, 7:31

23. Human Protein Atlas [http://www.proteinatlas.org/

24. Krause M, Ukkonen $K$, Haataja T, Ruottinen M, Glumoff T, Neubauer A, Neubauer P, Vasala A: A novel fed-batch based cultivation method provides high cell-density and improves yield of soluble recombinant proteins in shaken cultures. Microbial Cell Factories 2010, 9:11.

25. Kivirikko Kl, Myllyla R: Recent developments in posttranslational modification: intracellular processing. Methods Enzymol 1987 144:96-114

26. Rautio J, Barken KB, Lahdenperä J, Breitenstein A, Molin S, Neubauer P. Sandwich hybridisation assay for quantitative detection of yeast RNAs in crude cell lysates. Microbial Cell Factories 2003, 2:4

27. Thieme D, Neubauer P, Nies DH, Grass G: Sandwich hybridization assay for sensitive detection of dynamic changes in mRNA transcript levels in crude Escherichia coli cell extracts in response to copper ions. Appl Environ Microbiol 2008, 74:7463-7470.

doi: $10.1186 / 1475-2859-9-48$

Cite this article as: Osmekhina et al., Sandwich ELISA for quantitative detection of human collagen prolyl 4-hydroxylase Microbial Cell Factories 2010 9:48

\section{Submit your next manuscript to BioMed Centra and take full advantage of:}

- Convenient online submission

- Thorough peer review

- No space constraints or color figure charges

- Immediate publication on acceptance

- Inclusion in PubMed, CAS, Scopus and Google Scholar

- Research which is freely available for redistribution
C) BioMed Central 